\title{
Modified wheel tracker as a potential replacement for the current conventional wheel trackers
}

Mofreh Saleh

Associate Professor of Civil Engineering

University of Canterbury

Cryeke Road, Christchurch

New Zealand

DDI:6433695118

Tel.: 643642987 Ext 95118

Email: Mofreh.saleh@canterbury.ac.nz 


\begin{abstract}
This research introduces a modified method for the wheel tracker test. Conventionally, the test is conducted by placing asphalt slabs or cylindrical cores in a fully confined steel or polyethylene molds. The research work undertaken by the author has shown that having the specimen fully confined in all directions by the steel or polyethylene mold would limit or prevent it from lateral (shear) deformation. It is also well-known that shear related permanent deformation is identified as the primary cause for high severity rutting. As a result, a new wheel tracker test setup was designed and manufactured to capture the true material response under the applied load. In the conventional wheel tracker, the large majority of samples will only show the primary stage and very small part of the secondary stage of the permanent deformation curve and most of the time the curve will plateau regardless of the number of cycles applied. Therefore, in the conventional wheel tracker test, the tertiary stage never reached in the vast majority of the tested specimens. In the modified wheel tracker, the three stages of permanent deformations are always captured, therefore, the flow number can be determined. In addition, the effect of the major mix parameters and test conditions such as air voids content, aggregate gradation, binder type and test temperature can be captured and analyzed.
\end{abstract}

Key Words: Asphalt Mixture, Permanent Deformation, Loaded Wheel Tester, New Test Setup 


\section{INTRODUCTION}

Rutting is classified as one of the major structural failure in flexible pavements (Archilla and Madanat 2000). Rutting is defined as the accumulation of permanent deformations resulting from traffic loads to flexible pavement. Premature rutting will considerably reduce the remaining useful life of a pavement and will create a safety hazard in rainy conditions by causing hydroplaning or aquaplaning. The potential for rutting has increased due to the continuous increase in traffic volumes, axle weights and the increased use super single tyres which typically exhibit higher inflation pressures (Cooley et. al. 2000). The distress could be divided principally into three mechanisms; one dimensional densification, creep deformation and lateral flow or plastic movement. The latter, i.e. plastic deformation is acknowledged by researchers as the major type of permanent deformation caused by inadequate shear strength. High rutting severity level is, predominantly, the result of this mechanism (Witczak, 2007).

In order to study asphalt material behavior, National Cooperative Highway Research Program (NCHRP) recommended the Simple Performance Test (SPT) (Witczak et al. 2002,Witczak 2005). The SPT accounts for shear deformation by measuring the flow number or flow time under the repeated and/or static creep tests, respectively, which would occur at the start of the “tertiary phase". Studying asphalt material response under repeated load application reveals that the asphalt mixture permanent deformation curve can be divided into three major zones known as; primary, secondary and tertiary zones. In general, permanent deformation accumulates at a decreasing rate in the primary zone. This increment decreases reaching a constant value in the secondary zone and finally, it increases rapidly at the onset of the tertiary zone (Witczak, 2005). The inflection point between the secondary and tertiary zones on the deformation-number of cycle curve is referred to as the flow number or flow time on the deformation-time relationship. The tertiary point has two significant characteristics; first, permanent deformation rate undergoes a dramatic increase right after this point. Second, it occurs under the constant volume which signifies the pure shear based deformation.

One issue regarding the SPT test series is that, they are rather time consuming and they also require elaborate testing equipment. In addition, they are not intended for quality control and quality assurance (QC/QA) either. More important, one can also observe that none of the test loading sequences is any close to the actual traffic load. As a result, the public and private sectors continued working on developing a test apparatus with unsophisticated test mechanism to be used in mix preparation step as well as the QC/QA of pavement 
construction (Kandhal and Cooley, 2003). Thus, wheel tracker test setup and its loading pattern could better simulate the action of moving traffic wheel (Ahmad et. al. 201, Lu and Harvey 2006). Several types of loaded wheel trackers were developed and used in testing rutting resistance over the past years, this includes the Georgia Loaded Wheel Tester (GLWT), Asphalt Pavement Analyzer (APA), Hamburg Wheel Tracking Device (HWTD), LCPC (French) Wheel Tracker, Purdue University Laboratory Wheel Tracking Device (PURWheel), and other devices (Cooley et. al. 2000 ). These devices use similar principles with minor differences in the specimen dimensions and whether cylindrical or rectangular slabs are used, the applied load value and whether the load is applied via steel wheel or rubber tyre and whether the tyre is sold rubber tyre or inflated tyre. Some of available devices apply loading wander on the specimen such as PURWheel.

Uzarowski, and Lum (2004) conducted laboratory study using Asphalt Pavement Analyzer; Hamburg Wheel Rut Tester; and the French Laboratory Rutting Tester to compare the performance of the asphalt mixes in the field with their ranking in three different rut wheel testers. The research work paper described the equipment, procedures, criteria and a potential use of the rut testers, however, the researcher did not provide final conclusions on the effectiveness of any of these devices.

Yildirim et. al (2007) investigated whether the Hamburg wheel-tracking device(HWTD) can be used to validate durability tests such as soundness and Micro-Deval tests. In this research, researchers concluded that based on soundness resistance and Micro-Deval tests do not correlate well with Hamburg test results. Authors also investigated the effects of aggregate, binder grade, mix type, and additive on HWTD results. The HWTD test parameters investigated included rutting, slope of the rutting curve, and the area beneath the rutting curve at specific cycles. Based on the results of the analysis, it was observed that the dominant factors influencing Hamburg test performance are those that stiffen the mix, particularly stiffer performance grades (PG) and additives such as lime.

Rahman and Hossain (2014) conducted comprehensive analysis on Hamburg Wheel Tracking Device (HWTD) test results from tests done at KSU and database of tests conducted at KDOT. They concluded that the number of wheel passes and rut depth from the HWTD test are significantly different for Superpave mixes with various RAP content. They also added that RAP mixtures with crushed gravel and sand considerably improve overall rutting behavior. Authors also indicated that aggregate type and binder source influence rutting behaviour of virgin Superpave mixtures. 
Romero and Stuart (1999) conducted full scale testing utilizing the Accelerated Linear Facility (ALF) at the Turner-Fairbank Highway Research Center (TFHRC) in McLean, Va., to determine which rutting test device offers the most accurate prediction of pavement rutting resistance. Specimens with the same material used in the 12 pavements tested by ALF were prepared and tested in the French Pavement Rutting Tester; the Georgia Loaded-Wheel Tester; the Hamburg Wheel-Tracking Device; and the Superpave Shear Tester, a servohydraulic device. The lab results for each rutting test device were then compared to the full scale results provided by the ALF testing facility. The authors concluded that the comparisons showed that no device was clearly better than the others, not even the Superpave Shear Tester (SST). They also added that all devices were able to separate good from bad mixtures when these had been made with the same aggregate and different binders (ranging from a very soft PG 58 to a very stiff PG 78). However, when mixtures with two different aggregate gradations (nominal maximum aggregate of 19 millimeters and 37.5 millimeters) were tested, no device was able to distinguish the mixtures that performed well from those that did not, even though ALF testing showed significant differences in performance. This clearly shows the limitation of the current conventional wheel trackers.

Buy studying available literature, it obvious that the common issue between all current loaded wheel trackers is that specimens are tested fully confined inside the test mould. This fully confined condition creates very different boundary condition from that exists in the actual field. In addition, the fully confined conditions create very complex and variable state of stresses within the specimen during the test as it will be discussed later in the following paragraphs.

The aim of this paper is to introduce a new test setup for the wheel tracker test. The new setup in addition to measuring vertical deformation, it will also take into account the lateral displacement. In the modified wheel tracker, the lateral stresses can be controlled which allows for shear deformations to happen and therefore all three permanent deformation phases can be captured.

\section{SPECIMEN PREPARATION}

Asphalt mixes with 14 and $20 \mathrm{~mm}$ nominal maximum aggregate size were prepared for the experimental stage. These are commonly used hot mix asphalts in New Zealand. Slab shape specimens are used in wheel tracker test. Slab specimens of $305 \times 305 \times 50$ and $75 \mathrm{~mm}$ were considered for AC 14 and 20, respectively (Australian Standard, 2005). The aggregates, 
binders and job mix formula were secured from a local contractor who designed these mixes for one of the heavily trafficked Motorways in Christchurch - New Zealand. Asphalt mixtures were prepared based on the Australian standard AS 2891.2.1 "Methods of Sampling and Testing Asphalt" (Australian Standard, 1995, Austroads 2012). Accordingly, the asphalt cements were mixed and compacted at $150{ }^{\circ} \mathrm{C}$. All mixtures were also aged at $150{ }^{\circ} \mathrm{C}$ for one hour before compaction. The mixtures are compacted using European standard roller compactor.

\section{LIMITATIONS OF THE CONVENTIONAL WHEEL TRACKER TEST SETUP}

Figure 1a illustrates the conventional wheel tracker test setup. As shown in Figure 1a and 1b, considering the current wheel tracker test setup, the asphalt specimen is fully confined by the steel mold at all the four sides causing reactive pressure to build up at the sides of the specimen as the specimen tries to flow laterally during loading. The same issue exits with HWTD cylindrical specimens in which specimens are fully confined inside Polyethylene mold. The current AASHTO T324-17 test standard method for Hamburg wheel-track testing of compacted asphalt mixtures recommend using plaster to a height equal to that of the specimen to fill the air space between the specimen and the sides of the mounting tray; this to ensure full confinement of the test specimen.

Figure 1a Current wheel tracker test mold

Figure $1 \mathrm{~b}$ Confining stresses build up in conventional wheel tracker test

In order to quantify the magnitude of the lateral stresses exerted on the asphalt concrete slab specimen in the conventional wheel tracker test, a major redesign of the test apparatus were carried out at the University of Canterbury. The new modified wheel tracker design is patented under patent application number PCT/NZ2017/050088. In the modified wheel tracker, the mold is designed to allow lateral forces to be measured in the confined test set up as shown in Figure 2b. In addition, the test can be conducted under semi-unconfined conditions with the lateral permanent deformation recoded with the number of cycles. Figure $2 \mathrm{~b}$ shows the reactive force measured during the confined test set up as recorded by the 
temperature compensated load cell attached to moveable side plate of the modified mold design. It is obvious from Figure $2 \mathrm{~b}$ that the lateral reactive forces are building up during the test and reaches a maximum value. This provides strong evidence that the state of stresses during the conventional wheel tracker test is variable rendering the test less useful and fundamentally inaccurate. The buildup of this considerably high lateral confining stress will unrealistically boost the permanent deformation resistance of the mixes and limit the ability of the wheel tracker test to produce any valuable information about the effect of mix parameters such as air voids content or binder content on permanent deformation resistance. Therefore, by having the specimen fully constrained at all sides will cause the mold to apply large reactive pressure which will severely limit the slab from lateral (shear) deformation that would have occurred for a similar but semi unconfined slab. Therefore, running the wheel tracker test and measuring the deformation in the conventional setup would merely indicate measuring rutting caused by densification (i.e. compaction) as a result of air voids change as it will be explained more in the following sections.

Figure 2a

Figure $2 b$ 


\title{
MODIFIED WHEEL TRACKER TEST SETUP
}

\author{
Introducing New Test Setup
}

A modified version of the wheel tracker was designed at the Transportation Laboratory at the University of Canterbury and it is used for the accelerated performance testing. The machine includes a single solid rubber wheel. The tyre width is $50 \pm 1 \mathrm{~mm}$ which applies $700 \mathrm{~N}$ load. The average speed is 26.5 cycles per minute. The test is carried out in a temperature controlled chamber.

The new test setup is designed to permit the specimen to be tested either fully confined as the current conventional method or semi unconfined from the lateral sides as shown in Figure 3 or at any other intermediate pressure between 0 to $150 \mathrm{kPa}$. To record the horizontal deformation, two Dial Test Indicators (DTIs) are mounted on the specimen sides. One vertical Linear Variable Differential Transformer (LVDT) is also placed under the wheel tracker arm to measure the vertical deformation. The data acquisition system is designed to collect the vertical and the two horizontal deformations with the number of cycles.

Figure 3

To examine the effect of the lateral confining stresses on the wheel tracker test results, several specimens were prepared and tested in both the fully confined and the semi unconfined mode. Table 1 shows six slabs made with different binder types 60/70 and 80/100, different aggregate gradations with maximum nominal sizes, $14 \mathrm{~mm}$ and $20 \mathrm{~mm}$, and different air voids content. The confined wheel tracker test was conducted at high temperatures (i.e. 50 and $60^{\circ} \mathrm{C}$ ) for $50^{\prime} 000$ cycles and the total permanent deformations were recorded and are shown in Table 1.

\section{Table 1}

Table 1 shows that the total permanent deformations accumulated after 50'000 cycles at 50 and $60{ }^{\circ} \mathrm{C}$ are quite small and not significantly different regardless of the aggregate gradation, binder type or test temperature. None of the test specimens showed any sign of inflection point, therefore, to reach the tertiary stage for rutting using the fully confined test setup is unlikely. It is also quite apparent that the wheel tracker test results for the fully confined 
condition are difficult to analyze, thus, they will not provide useful information to rank the permanent deformation resistance of the tested mixes. Based on the test results shown in the table 1 , one will easily mistakenly conclude that changes of the major mix parameters and test conditions would have no significant effect on the permanent deformation mixtures response. The unrealistic confining stresses generated in the confined setup of the wheel tracker test will cause the final permanent deformations to be much smaller than what it would be expected under a more realistic confining condition. The measured permanent deformations shown in Table 1 are quite close regardless of the test temperature and the aggregate gradations (AC14 and AC20) and binder type 60/70 and 80/100. This predicament with the wheel tracker test was also reported in the literature by other researchers (Shami et. al., 1997,Yildirim et. al. 2007). Moreover, authors faced the very same discussions while consulting the matter with pavement industry practitioners.

Figures $4 \mathrm{a}$ to $4 \mathrm{~d}$ show the results of the wheel tracker test carried out on two identical pair of slabs in the fully confined and the semi unconfined mode. All the slabs in Figures $4 \mathrm{a}$ to $4 \mathrm{~d}$ were made of AC20 mixes, with one pair of slabs used soft binder 80/100 penetration grade and air voids content $6.0 \%$ while the other pair used a harder binder grade 60/70 and lower air voids content of $4.3 \%$. All slabs were tested at $50{ }^{\circ} \mathrm{C}$. It is clear from Figures $4 \mathrm{a}$ and $4 \mathrm{c}$ that the permanent deformation in the fully confined mode plateau at $2.0 \mathrm{~mm}$ regardless of the binder type or air voids content. Figures $4 \mathrm{~b}$ and $4 \mathrm{~d}$ carried out on two identical specimens to that used in Figures $4 \mathrm{a}$ and $4 \mathrm{c}$, respectively but in the semi unconfined mode. The semi unconfined test results clearly showed significant difference between the two mix types. The AC20 mix made with the harder bitumen of 60/70 binder and with $4.3 \%$ air voids content lasted almost double the number of cycles compared to the same AC20 mix with softer binder of $80 / 100$ and with higher voids content of $6.0 \%$ to reach the tertiary flow. This clearly demonstrates that the new test set up is more capable of detecting the effect of the important mix parameters such as air voids content, binder type, and aggregate gradations on the permanent deformations.

Figure $4 \mathrm{a}$

Figure $4 b$

Figure $4 \mathrm{c}$

Figure 4d 
As can be seen from the above discussions, the excessive confinement exerted on the asphalt mix by the steel mold in the conventional wheel tracker test is one of the most important obstacles preventing the true material behavior. In addition, the fully confined test will most likely be able to capture the small part of the permanent deformation related to the mix densification and it will not likely be able to capture the shear related permanent deformations. This finding agrees with Azri et. al. (2015) study in which the authors conducted the wheel tracker test on several lab and field mixtures and they concluded that, apart from two outlier results, all mixtures did not exhibit inflection point. In addition, the authors attributed the inflection point or tertiary failure of the two outliers to the loosening of the bolts holding specimens in test trays which was reported by the laboratories in which the wheel tracker test was conducted. In fact, based on the above discussions, the author hypothesized that this loosening of the bolts eased the confining pressure in these two specimens compared to other specimens that were fully confined and therefore the tertiary failure was mobilized in these two specimens. Consequently, the author decided to use the new modified test setup to better characterize permanent deformation behavior.

\section{SENSITIVITY TO THE MIX VOLUMETRIC PROPERTIES AND TEST TEMPERATURE}

In order to investigate the effectiveness of the modified wheel tracker test setup to mix volumetric properties and the test temperatures, 20 tests with two replicates for each test were conducted. A total of 40 slabs of two different aggregate gradations (AC20 and AC14) and two different binder types $60 / 70$ and 80/100, two different test temperatures 50 and $60{ }^{\circ} \mathrm{C}$ and different air voids content were prepared as shown in Table 2. To guarantee capturing a complete deformation curve, the wheel tracker experiment was conducted to run up to $100^{\prime} 000$ cycles or $15 \mathrm{~mm}$ vertical deformation, whichever occurs first. The horizontal and vertical deformations and the number of cycles were recorded. Both horizontal and vertical permanent deformations and the number of cycles were modeled by Francken model given by Equation 1.

$\delta=A^{*} N^{B}+C^{*}\left(e^{D N}-1\right) \quad$ Equation 1

$\delta=$ permanent deformation 
$\mathrm{N}=$ number of wheel track loading cycles

$\mathrm{A}, \mathrm{B}, \mathrm{C}$ and $\mathrm{D}=$ Regression constants depending on the mix properties

Figure 5a shows the experimental data displayed as broken line curve and the Francken model predicted data represented by solid line superimposed on the same graph for both vertical and horizontal permanent deformations. The Francken model provided an excellent fitting for the experimental data for the three phases of deformation: primary, secondary and tertiary. In order to achieve more information about the permanent deformation behavior of the mixes, the rate of change of permanent deformation given by Equation 2 was plotted against the number of cycles as shown in Figures 5a to $5 \mathrm{~h}$.

$\frac{d \delta}{d N}=A B N^{B-1}+C D e^{D N}$ Equation 2

Figures $5 \mathrm{a}$ to $5 \mathrm{~h}$ show the results of the rate of permanent deformation versus the cycle number for 6 tests out of the 20 tests conducted utilizing the modified wheel tracker test setup.

As the figures from $5 \mathrm{a}$ to $5 \mathrm{~h}$ and the data in Table 2 illustrate, by using the modified test setup, every single slab reaches its failure point, with only very few exceptions. That was not the case for the conventional test method. Moreover, unlike the fully confined approach, the semi unconfined wheel tracker test becomes more sensitive to mix parameters such as air voids contents, aggregate gradation, binder type and also to the test temperature. Therefore, ranking the mixtures based on their permanent deformation behavior becomes more reliable.

Comparing the rate of permanent deformations for coarse mix AC20 with medium gradation mix AC14 with both mixes having an air voids content of $7.0 \%$ and tested at the same temperature $50^{\circ} \mathrm{C}$, it is clear that the coarse mix is outperforming the medium mix in the permanent deformation behavior. Both horizontal and vertical permanent deformation provided the same conclusion. In addition, the rate of change of permanent deformation of both horizontal and vertical deformations provided useful information on how the permanent deformation developed in the loaded slab. The vertical permanent deformation starts at higher rate of deformation than the horizontal permanent deformation until certain point after which the horizontal permanent deformation overtakes the vertical deformation. The author 
designates this point as the critical point $\left(\mathrm{N}_{\mathrm{c}}\right)$ which is defined as the number of cycles at which both vertical and horizontal permanent deformation progress at the same rate. The critical point, $\mathrm{N}_{\mathrm{c}}$, can be determined as the point of intersection between the rate of vertical permanent deformation curve and the rate of the horizontal permanent deformation curve as shown in Figures $5 \mathrm{~b}$ to $5 \mathrm{~h}$.

Beyond the critical point, the horizontal deformation will progress at a faster rate until failure. Before the critical point, the mix will densify with rapid change of the air voids content, thus moving faster downward rather than moving laterally, therefore, the vertical deformation will progress at a faster rate than the horizontal deformation. Beyond the critical point, the mix will move laterally at a faster rate with more shear deformation until failure. In this study, the critical point $\mathrm{N}_{\mathrm{c}}$ has not been correlated to any specific mix performance or permanent deformation behavior but this can be investigated in future research.

With the modified wheel tracker test set up, all three zones of deformation were captured for both vertical and horizontal deformations. The equivalent flow number from the modified wheel tracker test was calculated using the Francken model as shown in Table 2 (Biligiri, 2007). Data shown in Table 2 are the average of two replicates. The point of inflection on the Francken curve was determined as the flow number. The flow number calculated from the vertical permanent deformation is denoted as $\mathrm{N}_{\mathrm{v}}$ and the flow number based on the horizontal permanent deformation is denoted as $\mathrm{N}_{\mathrm{h}}$. Figure 6 portrays the relationship between the Flow number based on the horizontal and vertical deformations. The two flow numbers $\mathrm{N}_{\mathrm{h}}$ and $\mathrm{N}_{\mathrm{v}}$ are well correlated with a coefficient of determination $\mathrm{R}^{2}$ of 0.97 . It was also observed that $\mathrm{N}_{c}$ always comes in between $\mathrm{N}_{h}$ and $\mathrm{N}_{\mathrm{v}}$ as shown in Figures $5 \mathrm{~b}$ and $5 \mathrm{~h}$. The critical number, $\mathrm{N}_{c}$, can provide useful information regarding the mix lateral stability and therefore its rutting resistance, however, more research will be needed to thoroughly investigate different types of mixes with different volumetric properties and different test conditions.

Figure 5a

Figure 5b

Figure 5c

Figure 5d 
Figure 5e

Figure $5 f$

Figure $5 \mathrm{~g}$

Figure $5 h$

Table 2

Figure 6

As can be seen from the above analysis presented in Figures $5 \mathrm{a}$ to $5 \mathrm{~h}$ and the data in

Table 2

2 above, the semi unconfined wheel tracker test setup provided wealth of information to characterize the permanent deformation behavior. In addition, the measured parameters from the vertical and horizontal permanent deformations showed sensitivity to the mix parameters and test temperatures. For example, the change of aggregate gradation from coarse to fine aggregate, i.e. AC 20 to 14, the mix undergoes higher deformation rate. The conclusion also applies to binder grade, $60 / 7$ to $80 / 100$, air voids, 3.5 to $7.0 \%$, and temperature, 50 to $60{ }^{\circ} \mathrm{C}$.

Furthermore, by comparing the ratio of the flow numbers based on horizontal to vertical deformations $\left(\mathrm{N}_{\mathrm{h}} / \mathrm{N}_{\mathrm{v}}\right)$ for all mixes at different temperatures, it was found that this value ranges from as low as 0.51 and as large as 0.84 . This means the horizontal deformation can be used in lieu of vertical deformation to shorten the test time from $15 \%$ to $50 \%$.

\section{CONCLUSIONS}

The effect of confining pressure on the slab specimens in the loaded wheel tracker was investigated. The confining reactive force was measured utilizing load cell and modified mold assembly which allows moveable plate which can move against a load cell. It was observed that this confining reactive force is variable and increase with the number of load cycles. The variable lateral pressure and the buildup of confining stresses render the conventional wheel tracker test as inaccurate and less useful in characterizing the permanent 
deformation behavior. A modified wheel tracker test setup with semi unconfined configuration was studied in this paper. The experimental data of the current conventional fully confined wheel tracker showed that undertaking the experiment under the fully confined setup will only lead to permanent deformation as a result of specimen densification (i.e. reduction in the air voids content). In addition, the conventional test setup was unable to detect the effect of mix parameters such as air voids content, aggregate gradations, bitumen grade, and test temperature on the permanent deformations behavior. To overcome these shortcomings, the semi unconfined setup was introduced in this study. In the modified semi unconfined setup, both horizontal and vertical deformations versus the number of cycles were recorded. The analysis of both horizontal and vertical deformations clearly showed that all three phases of permanent deformation: primary, secondary and tertiary were recorded for almost all mixes. The Francken model fitted both the horizontal and vertical permanent deformation exceptionally well over the three phases of deformations. The flow number based on the horizontal $\left(\mathrm{N}_{\mathrm{h}}\right)$ and vertical deformation $(\mathrm{Nv})$ were computed from the fitted data. In addition, the intersection between the rate of change of horizontal and vertical deformation curves was also determined and denoted as $\mathrm{N}_{\mathrm{c}}$. It was also noted that the ratio of the flow numbers based on horizontal to vertical deformations $\left(\mathrm{N}_{\mathrm{h}} / \mathrm{N}_{\mathrm{v}}\right)$ for all mixes at different temperature ranges from as low as 0.51 and as large as 0.84 . This means the horizontal deformation can be used in lieu of vertical deformation to shorten the test time from $15 \%$ to $50 \%$. The modified test setup generated a wealth of information that was not possible with the conventional test setup. The new modified wheel tracker design is patented under patent application number PCT/NZ2017/050088. 


\section{REFERENCES}

Ahmad, J., Abdul Rahman, M,Y., and Hainin, M., R. (2011). Rutting Evaluation of Dense Graded Hot Mix Asphalt Mixture. International Journal of Engineering \& Technology 11(05).

Archilla, A. R., and Madanat, S. (2000). Development of a pavement rutting model from experimental data. Journal of Transportation Engineering, 126(4), 291-299. doi: 10.1061/(asce)0733-947x(2000)126:4(291)

Australian Standard. (2005). Commentary to AG:PT/T220 - Sample Preparation Compaction of Asphalt Slabs Suitablel for Characterisation. Sydney: Standards Australia.

Australian Standard. (1995). Methods of Sampling and Testing Asphalt (Vol. AS 2891.2.1). Sydney: Standards Australia.

Austroads, Guide to Pavement Technology Part 2: Pavement Structural Design, ISBN 978-1921991-11-0, Sydney, Australia, 2012.

Azari, H., Mohseni, A., Precision of Hamburg Wheel-Track Test (AASHTO T 324), Transportation Research Board, Transportation Research Board Annual Meeting, 2015.

Biligiri, K. P., Kaloush, K. E., Mamlouk, M. S., and Witczak, M. W. (2007). Rational Modeling of Tertiary Flow for Asphalt Mixtures. Transportation Research Record: Journal of the Transportation Research Board, 63-72.

Lu, Q., and Harvey, J.T. (2006). Evaluation of Hamburg Wheel-Tracking Device Test with Laboratory and Field Performance Data. Transportation Research Record: Journal of the Transportation Research Board.

Kandhal, P.S., and Cooley, L. A. (2003). Accelerated Laboratory Rutting tests: Evaluation of the Asphalt Pavement Analyzer. Washington D.C.

Rahman, F. and Hossain, M. (2014) Review and Analysis of Hamburg Wheel Tracking Device Test Data Kansas Department of Transportation, Report No. KS-14-1.

Romero, P., Stuart, k. Evaluating Accelerated Rut Testers, FHWA Report Vol. 62 No. July/August 1998

Shami, H, I., Lai, J,S., D'angelo J,A, and Harman, T.P. (1997). Development of TemperatureEffect Model for Predicting Rutting of Asphalt Mixtures Using Georgia Loaded Wheel Tester. Transportation Research Record.

Uzarowski, L. and Lum, P. Accelerated Performance Testing of Canadian Asphalt Mixes Using Three Different Wheel Rut Testers, Accelerated Field and Laboratory Pavement Testing Session, Annual Conference of the Transportation Association of Canada, Quebec City, Quebec, 2004

Witczak, M.W. (2007). Specification Criteria for Simple Performance Tests for Rutting Volume I: Dynamic Modulus (E*) Volume II: Flow Number and Flow Time. WASHINGTON, D.C.

Witczak, M. W., Kaloush, K., Pellinen, T., El-Basyouny, M., \& Von Quintus, H. (2002). Simple Performance Test for Superpave Mix Design. Washington, D.C.

Witczak, M. W. (2005). Simple Performance Tests: Summary of Recommended Methods and Database. Washington, D.C.: Transportation Research Board.

Yildirim, Y., Jayawickrama, P. W., Hossain, M. S., Alhabshi, A., Yildirim, C.; Little, D. 
(2007) Hamburg Wheel-Tracking Database Analysis, Texas Department of Transportation, Report 0-1707-7, Project 0-1707. 
Figures

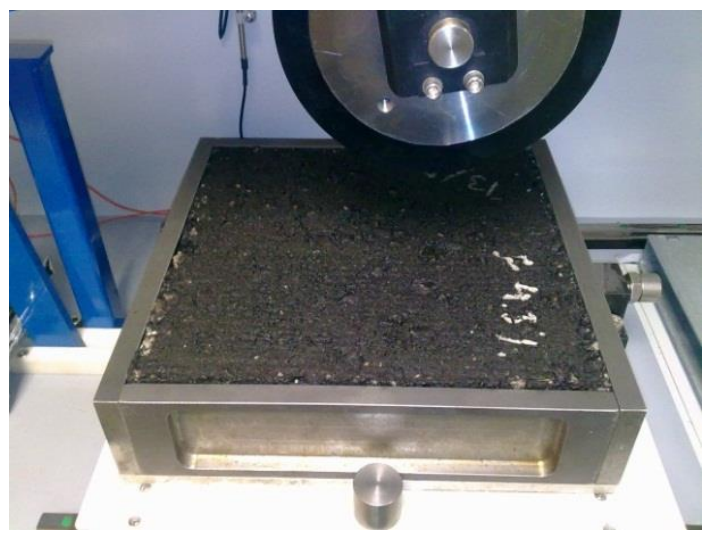

Figure 1a Current wheel tracker test mold 


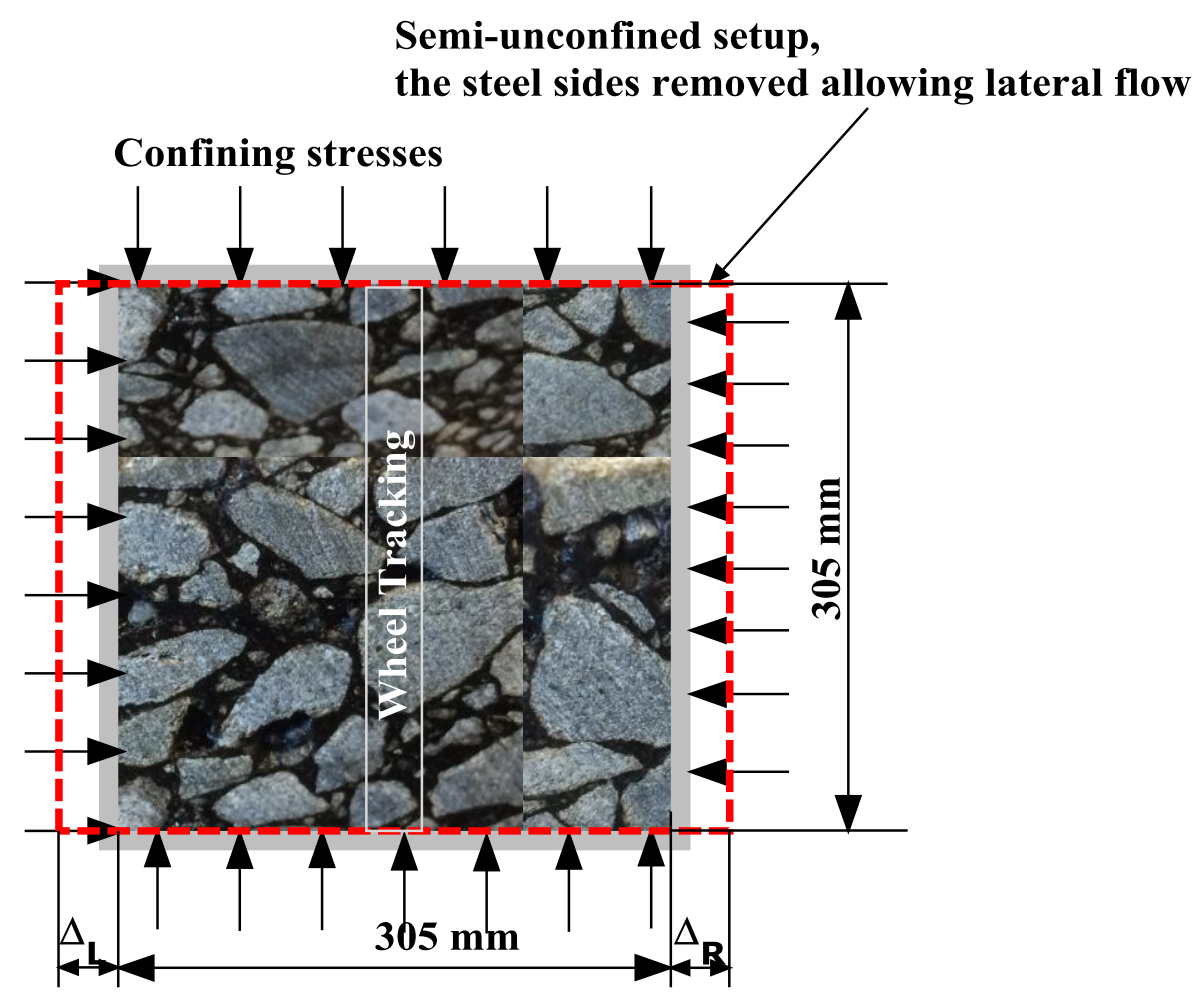

Figure $1 \mathrm{~b}$ Confining stresses build up in the conventional wheel tracker test 


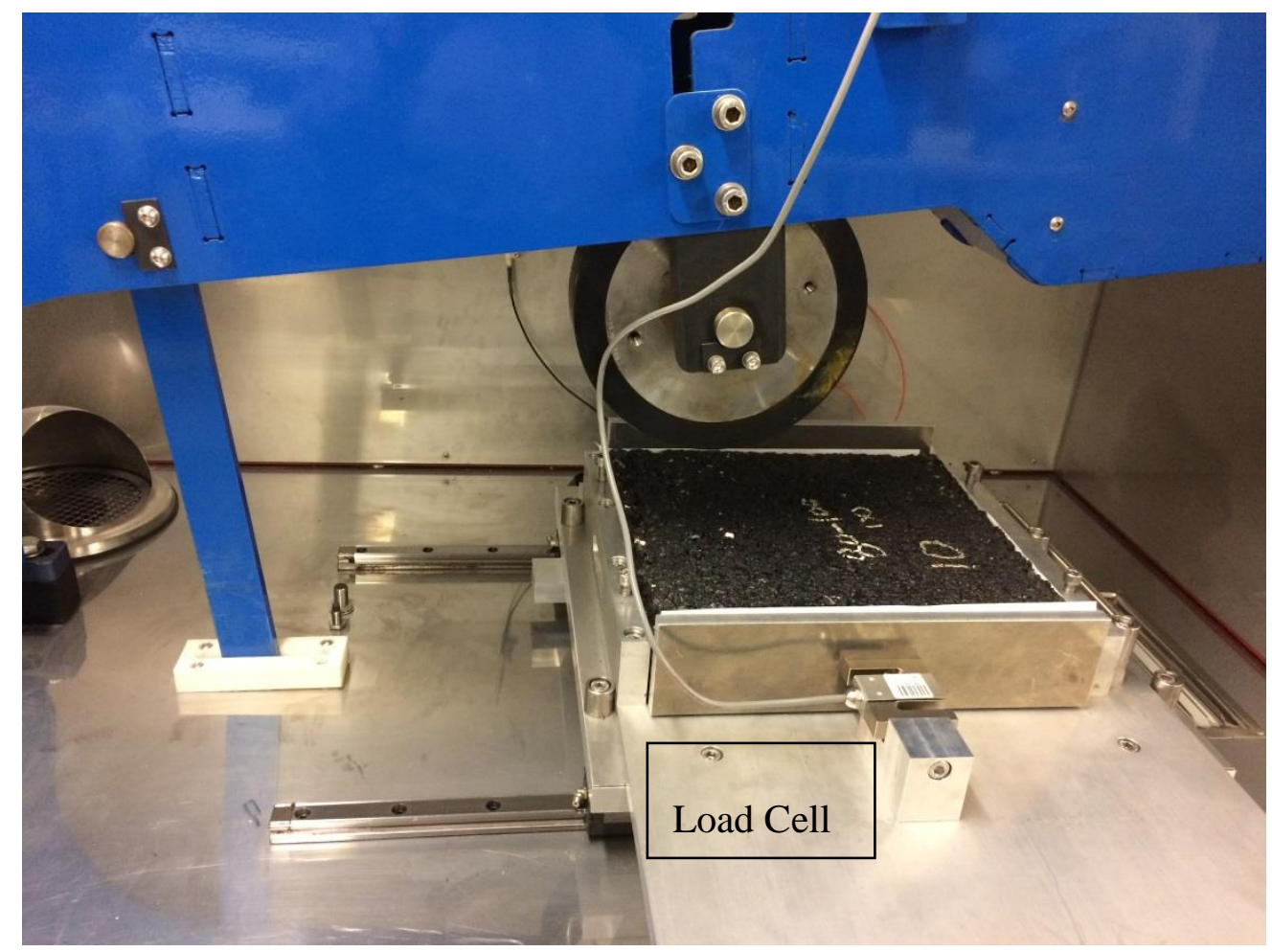

2a Measurement of lateral reactive force during the confined conventional wheel tracker test 


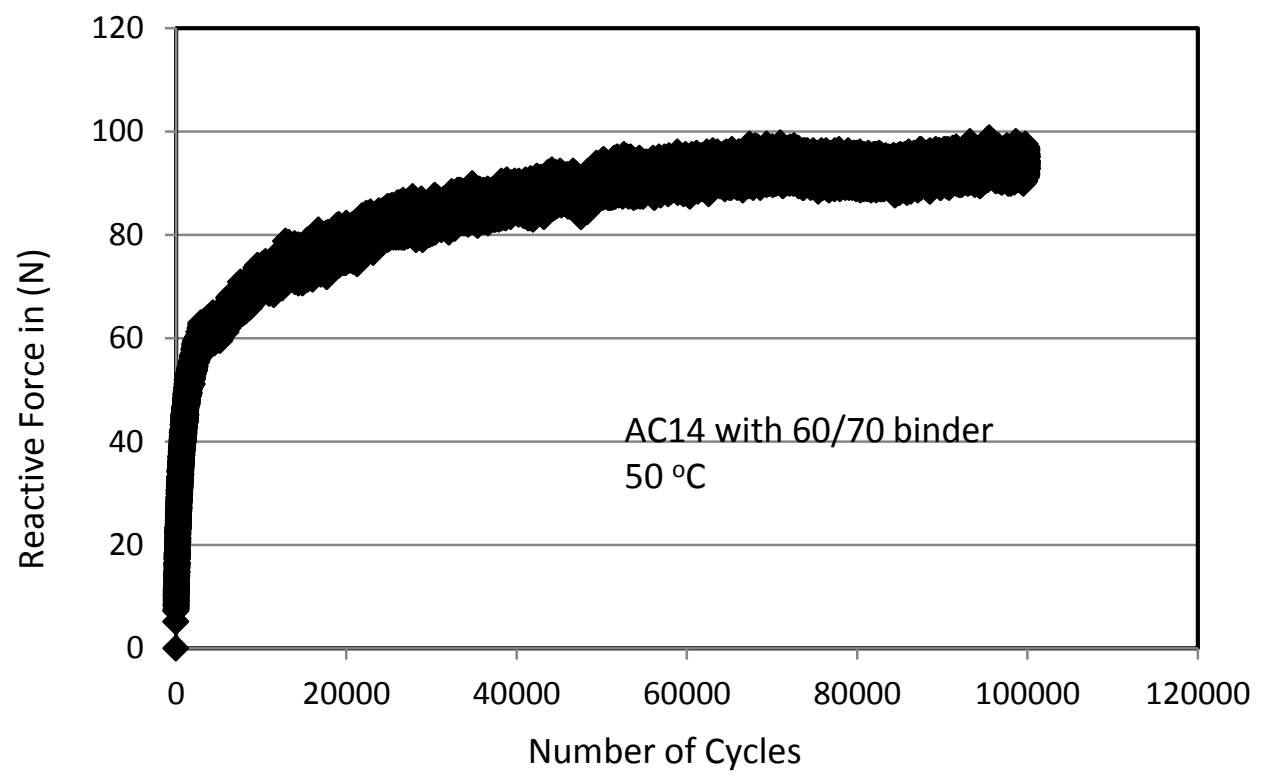

Figure $2 b$ Measurement of confining reactive force in Newton versus number of loading cycles 


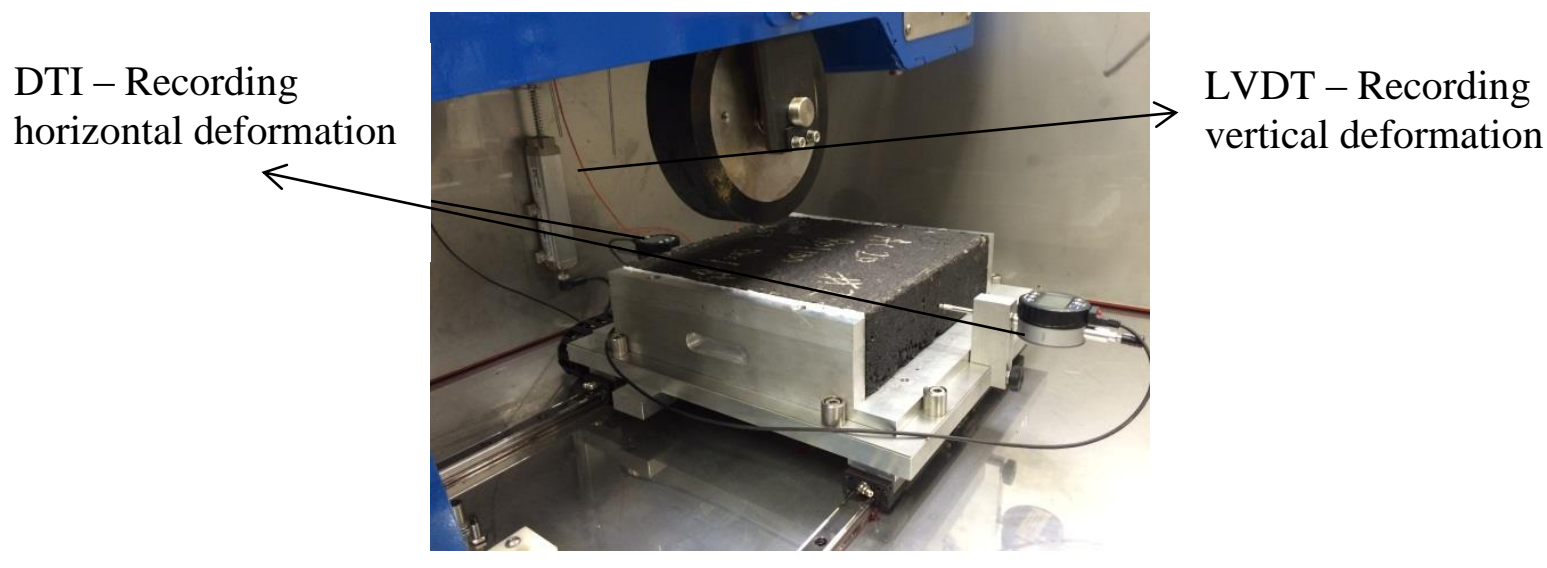

Figure 3 Semi-unconfined wheel tracker test setup 


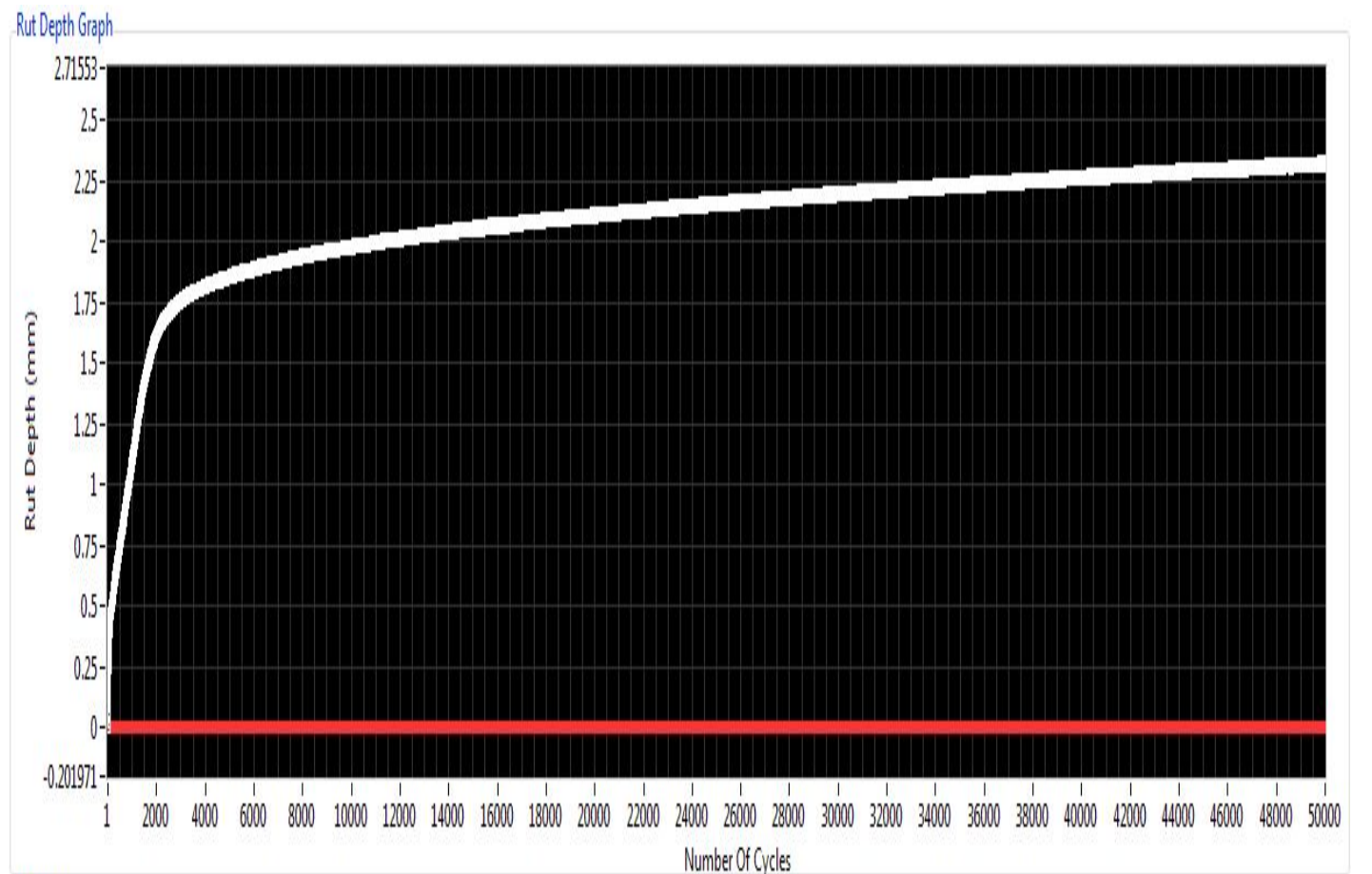

Figure 4a Conventional wheel tracker test for AC14 HMA with binder 80/100 and 6.0\% voids content 


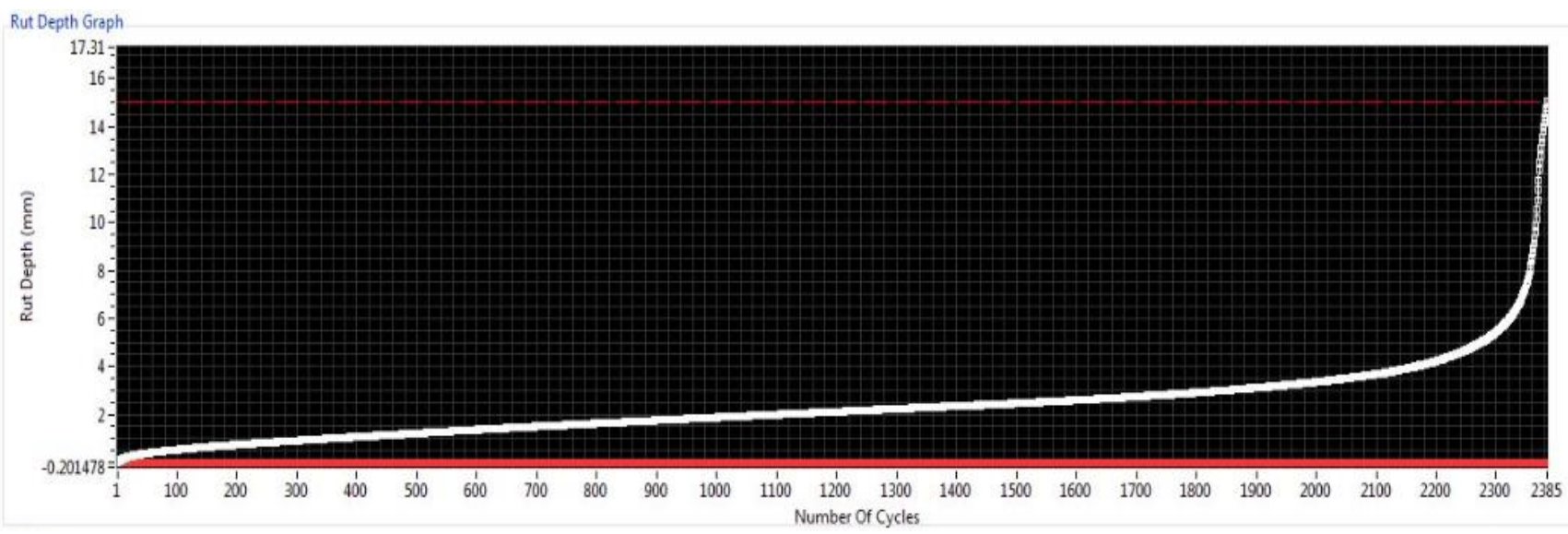

Figure 4b Semi unconfined wheel tracker test for AC14 HMA with binder 80/100 and 6.0\% voids content 


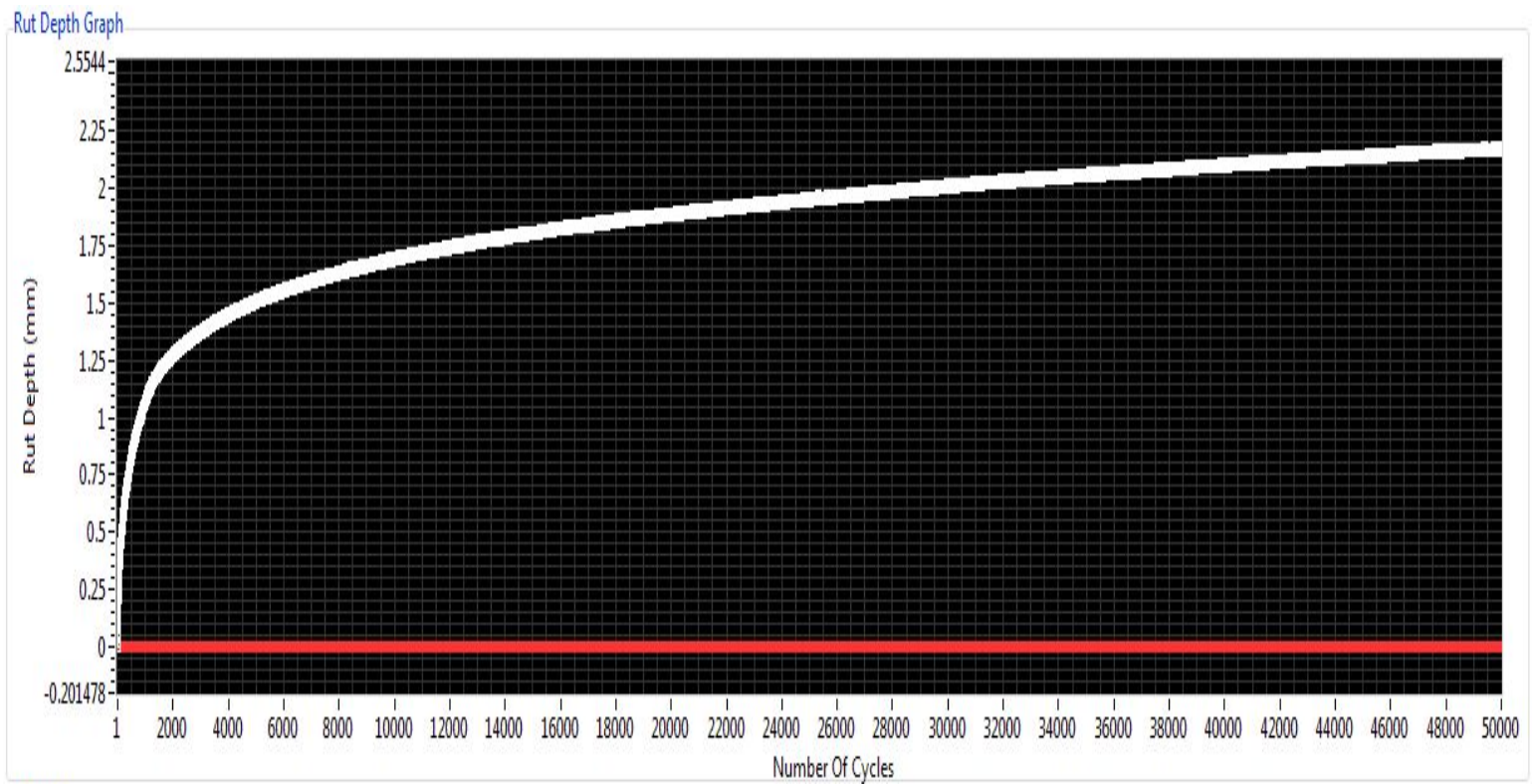

Figure 4c Conventional wheel tracker test for AC14 HMA with binder 60/70 and 4.3\% voids content 


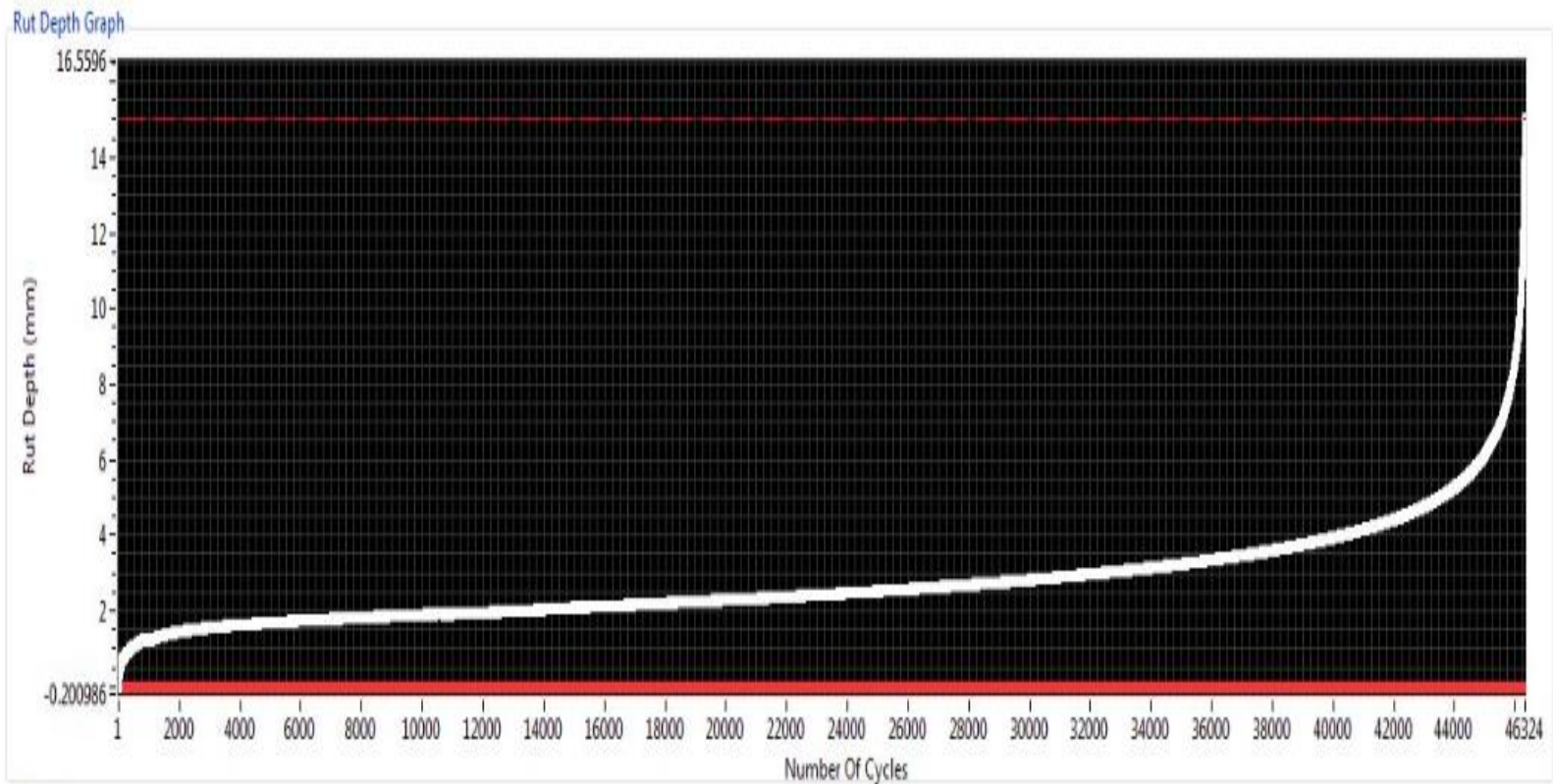

Figure 4d Semi unconfined wheel tracker test for AC14 HMA with binder 60/70 and 4.3\% voids content 


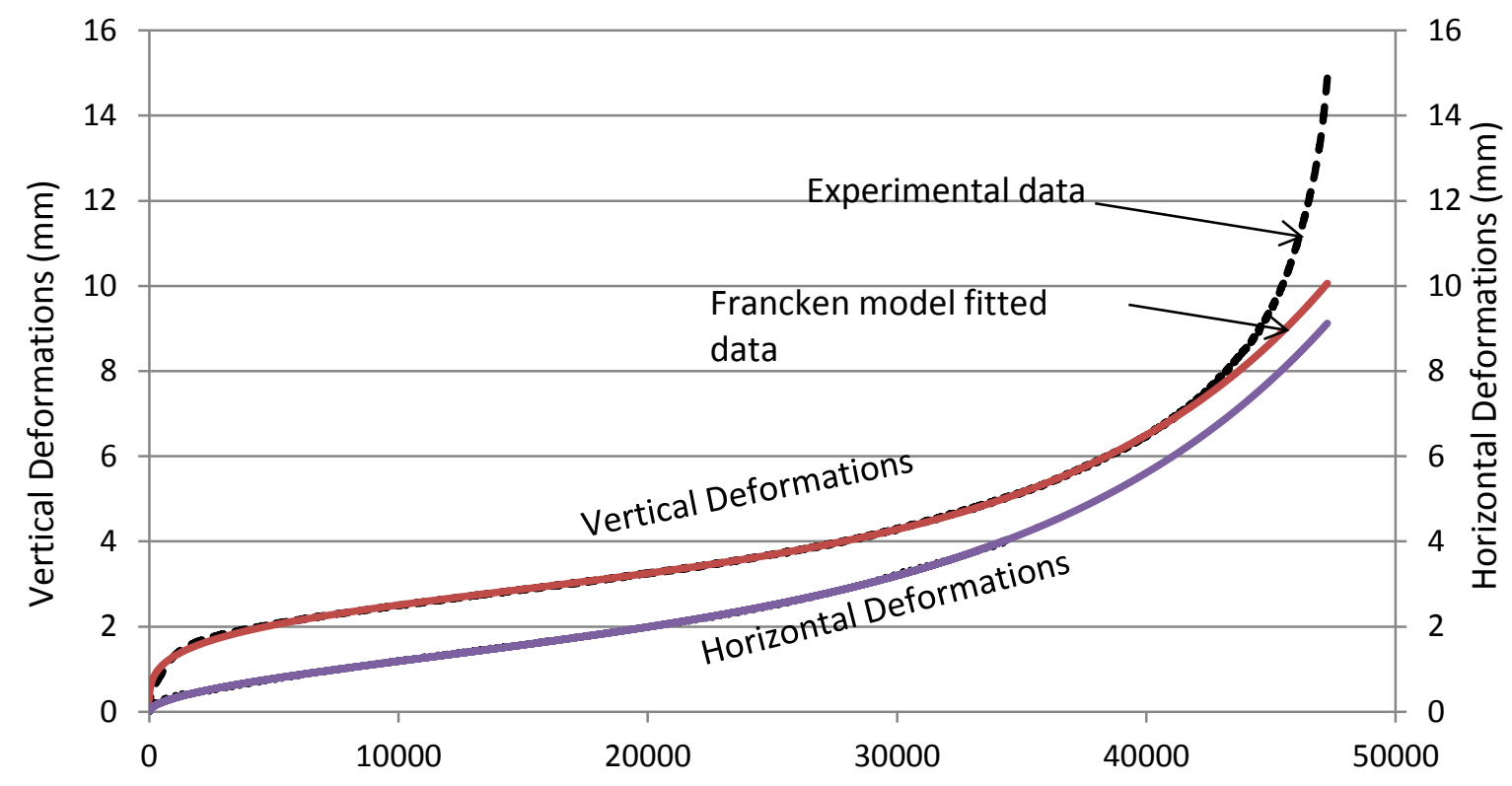

Figure 5a Permanent deformation versus cycle number for HMA with nominal max size 20 mm with binder $60 / 70$ and air voids content $7.0 \%$ at $50^{\circ} \mathrm{C}$ 


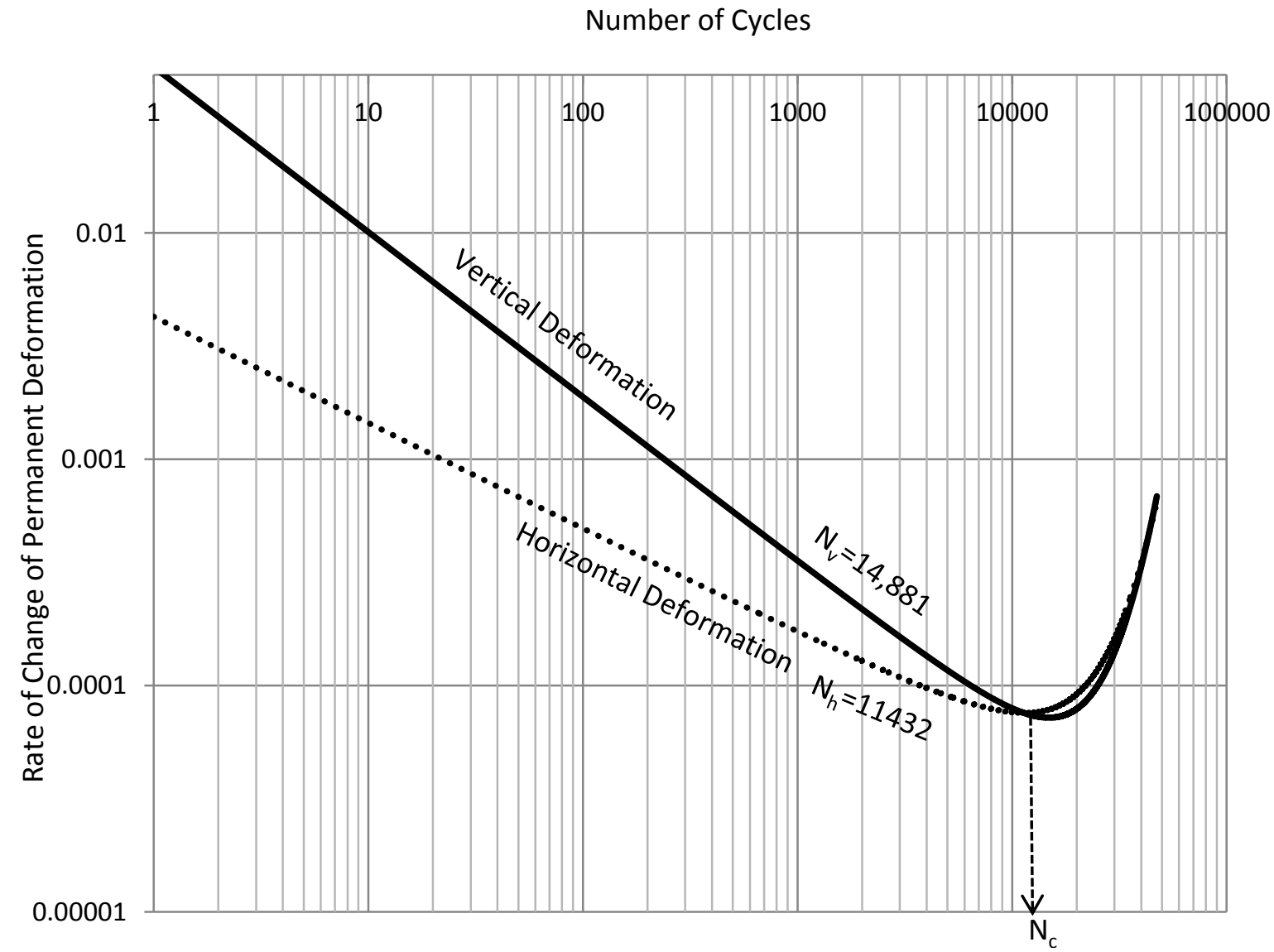

Figure $5 b$ Rate of permanent deformation versus cycle number for HMA with nominal max size $20 \mathrm{~mm}$ with binder $60 / 70$ and air voids content $7.0 \%$ at $50^{\circ} \mathrm{C}$ 


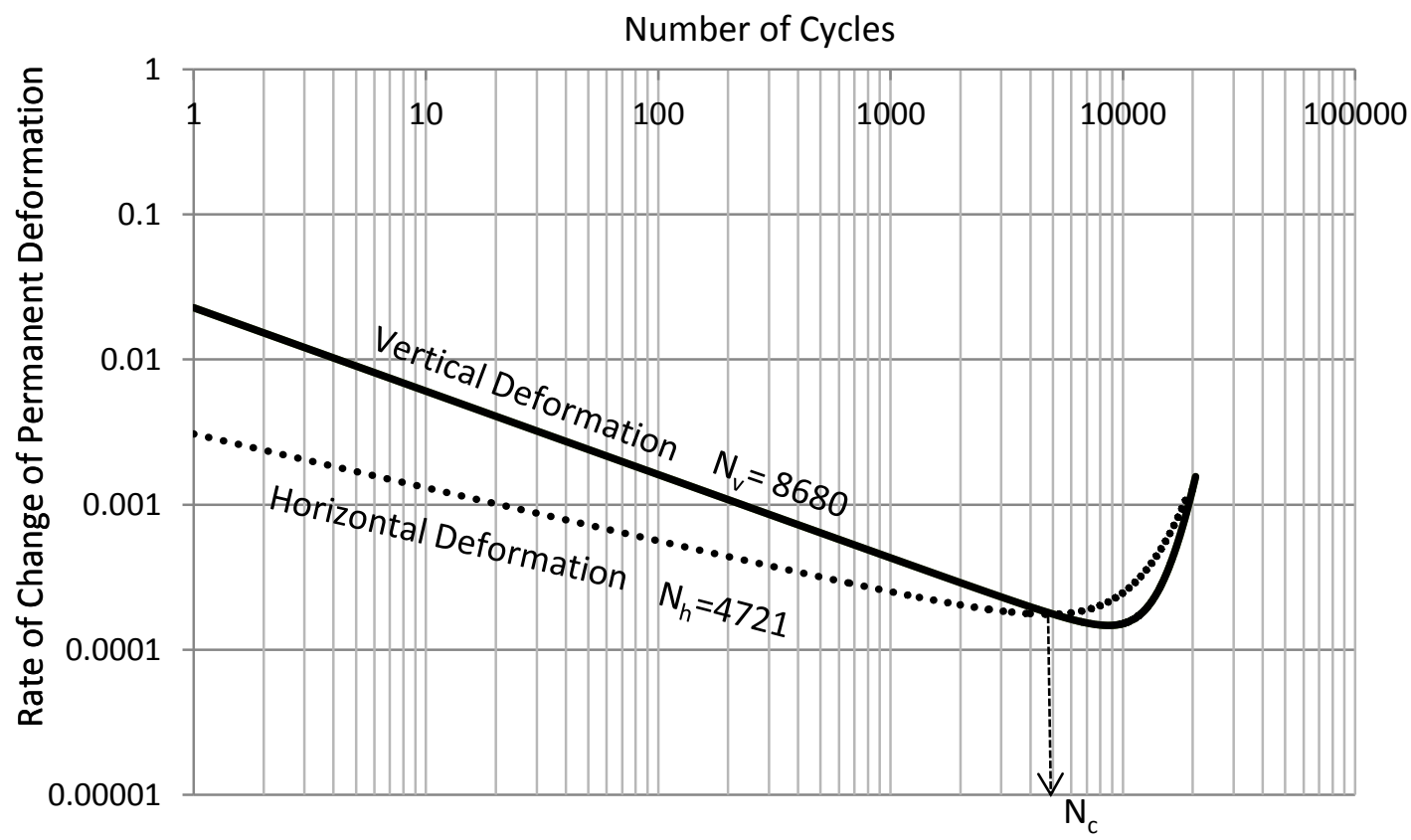

Figure 5c Rate of change of permanent deformation versus cycle number for HMA with nominal max size $14 \mathrm{~mm}$ with binder $60 / 70$ and air voids content $7.0 \%$ at $50^{\circ} \mathrm{C}$ 
Number of Cycles

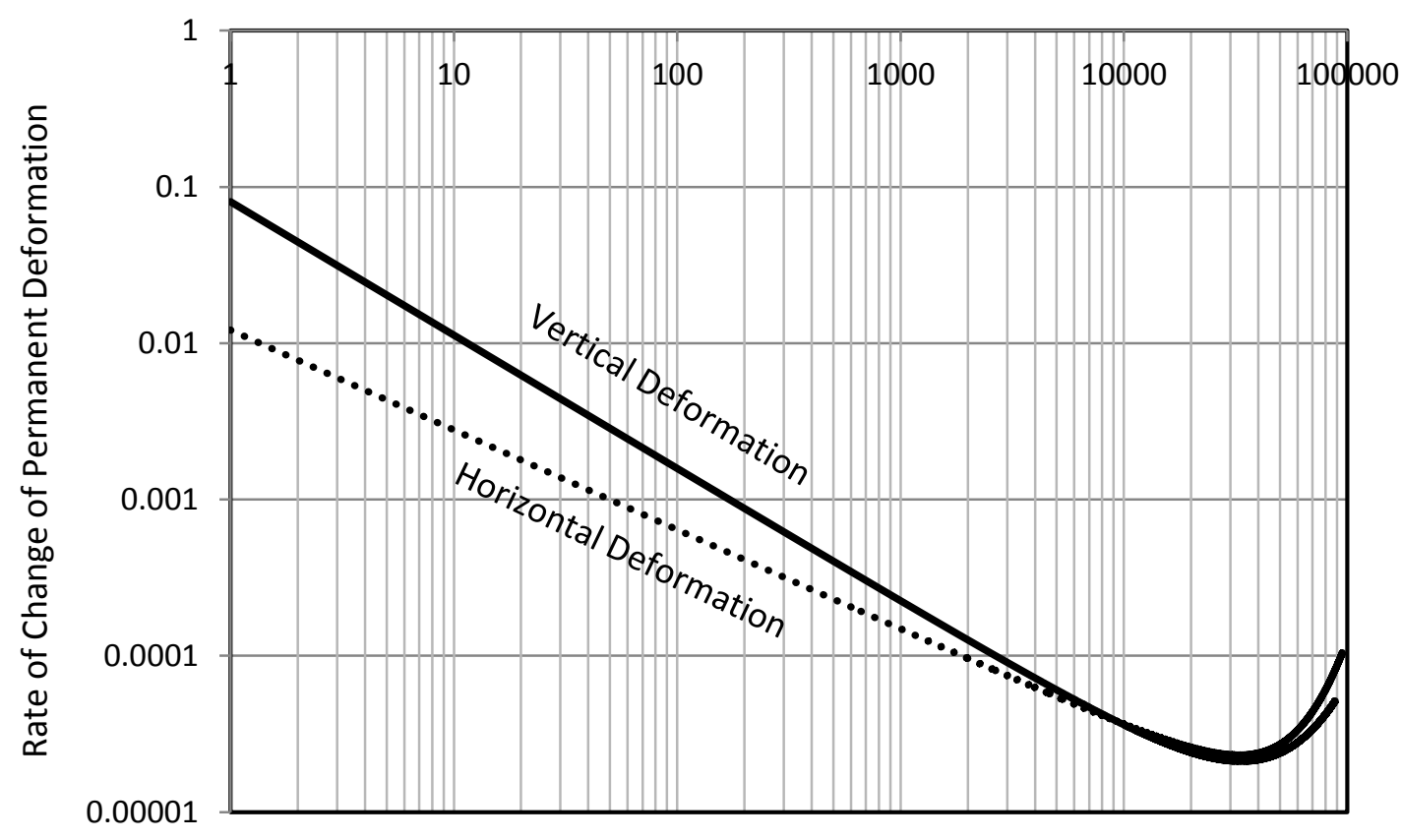

Figure 5d Rate of change of permanent deformation versus cycle number for HMA with nominal max size $20 \mathrm{~mm}$ with binder $60 / 70$ and air voids content $5.5 \%$ at $50^{\circ} \mathrm{C}$ 


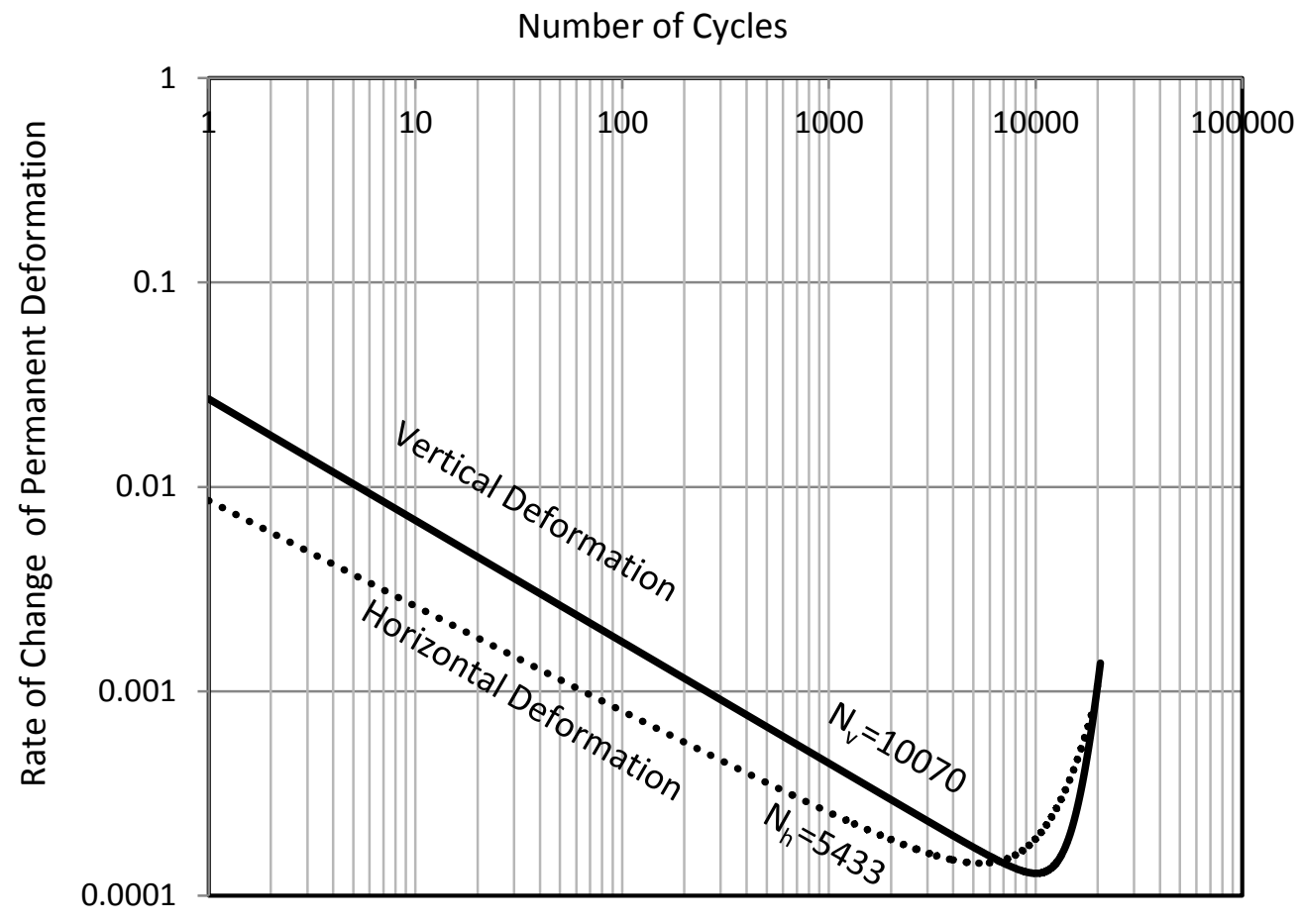

Figure 5e Rate of change of permanent deformation versus cycle number for HMA with nominal max size $14 \mathrm{~mm}$ with binder $60 / 70$ and air voids content $5.5 \%$ at $50^{\circ} \mathrm{C}$. 


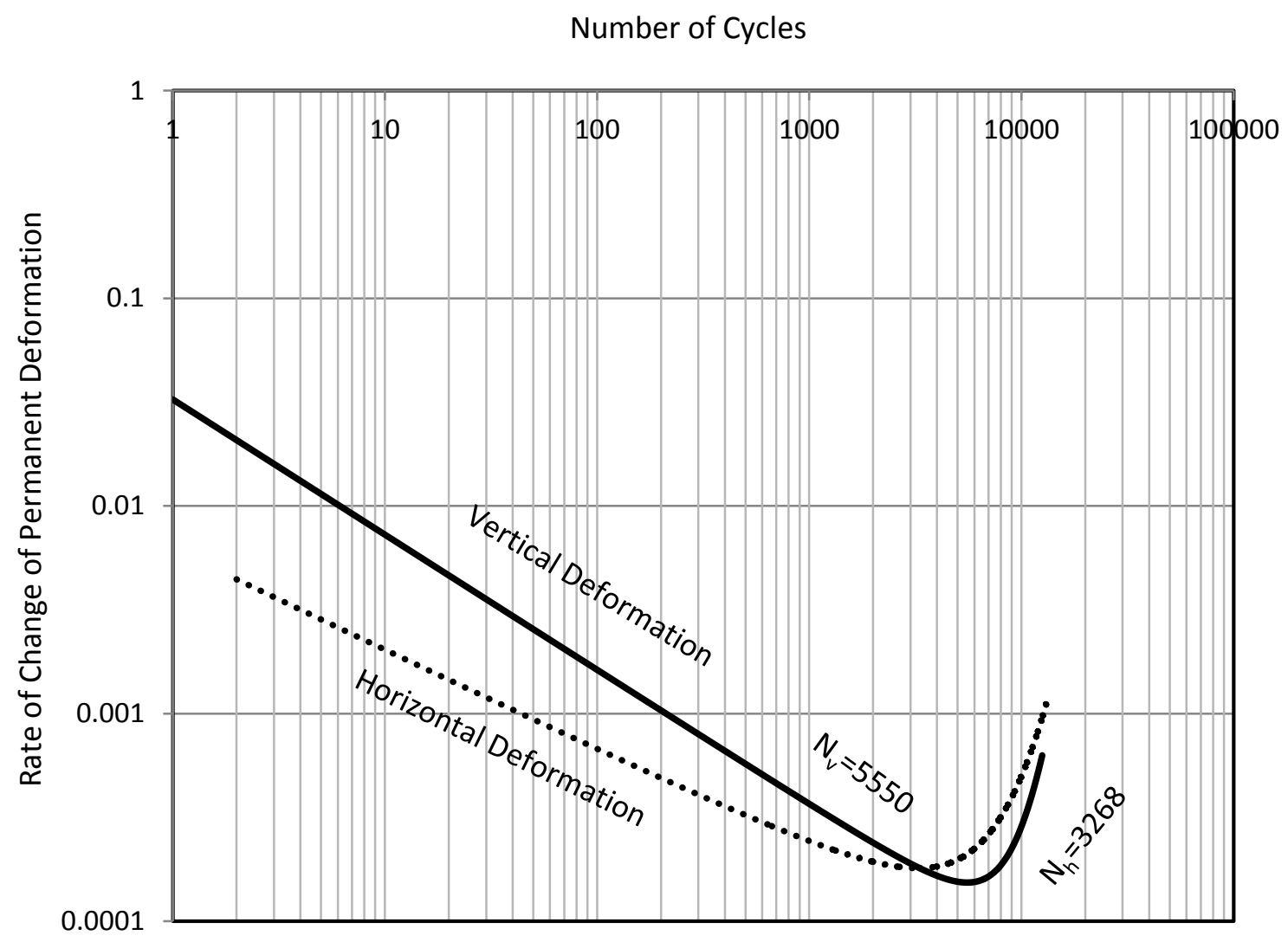

Figure $5 \mathrm{f}$ Rate of change of permanent deformation versus cycle number for HMA with nominal max size $14 \mathrm{~mm}$ with binder $80 / 100$ and air voids content $5.5 \%$ at $50^{\circ} \mathrm{C}$ 


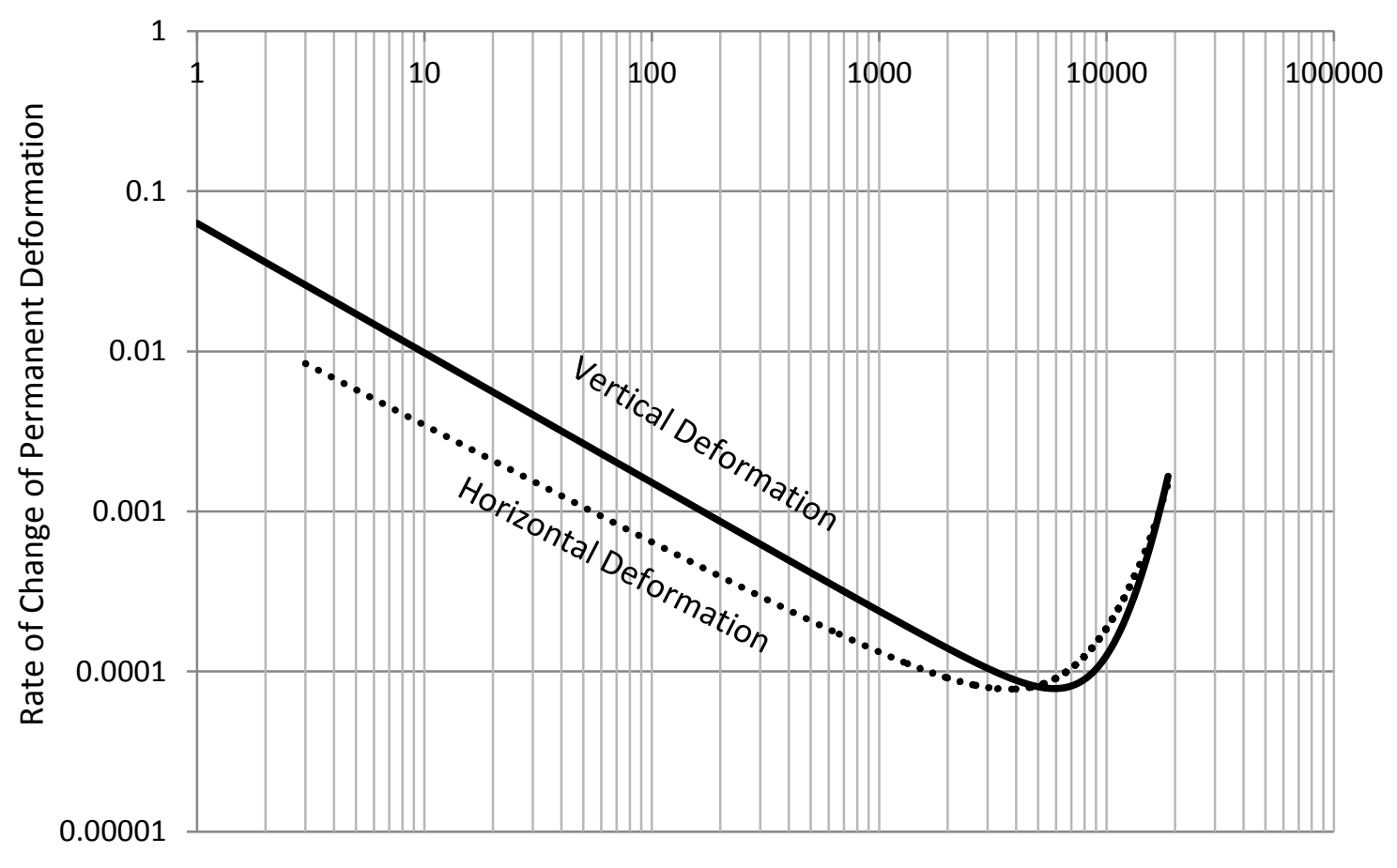

Figure 5g Rate of change of permanent deformation versus cycle number for HMA with nominal max size $14 \mathrm{~mm}$ with binder $60 / 70$ and air voids content $3.5 \%$ at $60^{\circ} \mathrm{C}$ 


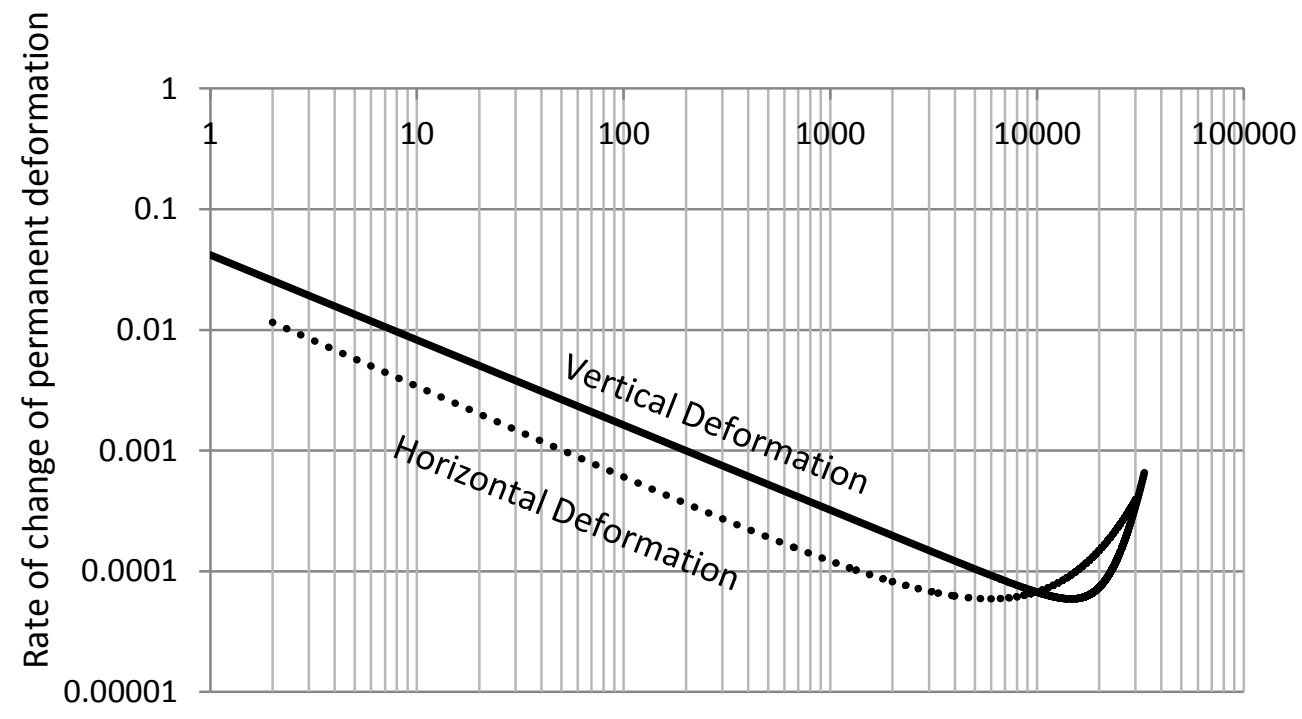

Figure 5h Rate of change of permanent deformation versus cycle number for HMA with nominal max size $14 \mathrm{~mm}$ with binder $60 / 70$ and air voids content $3.5 \%$ at $50^{\circ} \mathrm{C}$ 


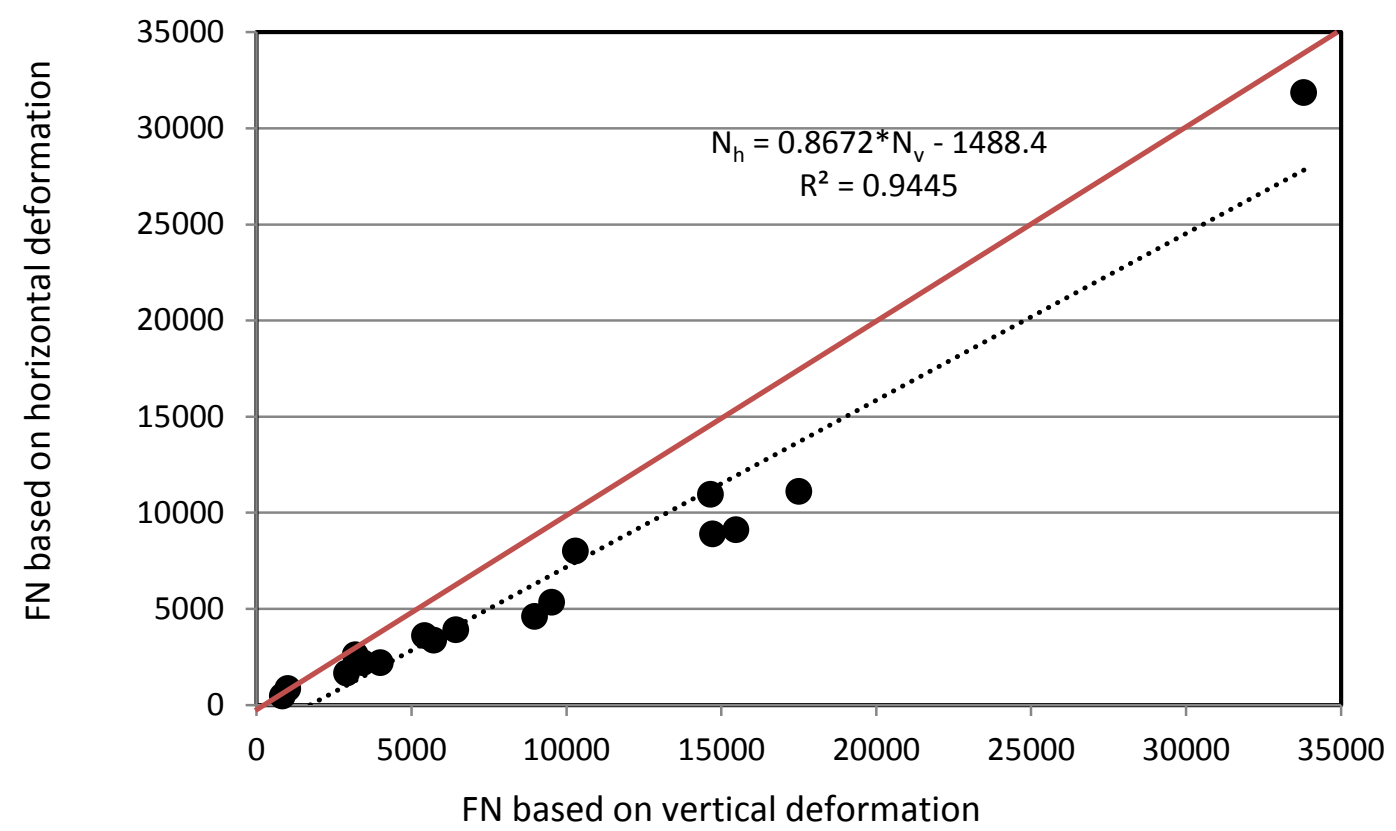

Figure 6 Flow number (FN) based on horizontal deformation versus FN based on vertical deformation 
Table 1. Wheel tracker test result in fully confined mode

\begin{tabular}{|c|c|c|c|c|}
\hline Gradation & Binder Type & Air Void $(\%)$ & Temperature $\left({ }^{\circ} \mathrm{C}\right)$ & Rutting $(\mathrm{mm})$ \\
\hline AC 14 & $60 / 70$ & 5.50 & 50.0 & 2.1 \\
\hline AC 20 & $80 / 100$ & 5.00 & 50.0 & 2.3 \\
\hline AC 20 & $60 / 70$ & 7.70 & 50.0 & 2.2 \\
\hline AC 14 & $80 / 100$ & 6.30 & 60.0 & 2.4 \\
\hline AC 20 & $80 / 100$ & 5.60 & 50.0 & 2.5 \\
\hline AC 20 & $60 / 70$ & 4.30 & 60.0 & 2.0 \\
\hline
\end{tabular}


Table 2. Vertical and horizontal flow number

\begin{tabular}{|c|c|c|c|c|c|}
\hline $\mathrm{T}\left({ }^{\circ} \mathrm{C}\right)$ & Mix Type & $\begin{array}{l}\text { Binder } \\
\text { Type }\end{array}$ & $\begin{array}{c}\text { Air } \\
\text { Voids } \\
(\%)\end{array}$ & $\begin{array}{c}\text { FN based on } \\
\text { vertical } \\
\text { deformation, } \mathrm{N}_{\mathrm{v}}\end{array}$ & $\begin{array}{c}\text { FN Based on } \\
\text { horizontal } \\
\text { deformation, } \mathrm{N}_{\mathrm{h}}\end{array}$ \\
\hline \multirow{12}{*}{50} & \multirow{6}{*}{ AC 20} & \multirow{3}{*}{$60 / 70$} & 3.5 & No failure & No failure \\
\hline & & & 5.5 & 33805 & 31850 \\
\hline & & & 7.0 & 14660 & 10960 \\
\hline & & \multirow{3}{*}{$80 / 100$} & 3.5 & No failure & No failure \\
\hline & & & 5.5 & 10300 & 7997 \\
\hline & & & 7.0 & 3190 & 2600 \\
\hline & \multirow{6}{*}{$\mathrm{AC} 14$} & \multirow{3}{*}{$60 / 70$} & 3.5 & 14725 & 8900 \\
\hline & & & 5.5 & 9530 & 5340 \\
\hline & & & 7.0 & 8980 & 4600 \\
\hline & & \multirow{3}{*}{$80 / 100$} & 3.5 & 6430 & 3900 \\
\hline & & & 5.5 & 5725 & 3360 \\
\hline & & & 7.0 & 2910 & 1660 \\
\hline \multirow{8}{*}{60} & \multirow{4}{*}{ AC 20} & \multirow{2}{*}{$60 / 70$} & 3.5 & 17510 & 11110 \\
\hline & & & 5.5 & 4000 & 2200 \\
\hline & & \multirow{2}{*}{$80 / 100$} & 3.5 & 15470 & 9100 \\
\hline & & & 5.5 & 3440 & 2200 \\
\hline & \multirow{4}{*}{$\mathrm{AC} 14$} & \multirow{2}{*}{$60 / 70$} & 3.5 & 5420 & 3600 \\
\hline & & & 5.5 & 1015 & 850 \\
\hline & & \multirow{2}{*}{$80 / 100$} & 3.5 & 3230 & 2300 \\
\hline & & & 5.5 & 840 & 460 \\
\hline
\end{tabular}

